\title{
Innovative Industrial Technologies for Preventive Anti-Graffiti Coating
}

\author{
Martin Heinisch ${ }^{1}$, and Dan Miricescu ${ }^{2, *}$ \\ ${ }^{1} \mathrm{MHI}$ Ingenieurgesellschaft mbH, B+H Solutions $\mathrm{GmbH}$ in 73630 Remshalden, Germany; also \\ visiting professor Engineering Faculty, Lucian Blaga University of Sibiu, Romania \\ ${ }^{2}$ Lucian Blaga University of Sibiu, Engineering Faculty, Sibiu, Romania
}

\begin{abstract}
Graffiti is the main issue in terms of acts of vandalism with public transport. Hardly any suburban train, commuter train or goods train, hardly any engineering building, station or noise barrier wall escape graffiti spraying. This means enormous expenses every year which one would rather use to the benefit of its customers. Furthermore, the temporary and permanent anti-graffiti protection systems used up to now do not ensure adequate graffiti protection. The costs for the application of graffiti protection and/or graffiti removal to a large part depend on the circumstances of the individual case in question, i.e. on the size of the surface, the type and size of the ground, the accessibility of the location and of the fact whether the graffiti need to be removed from unprotected or protected surfaces. A unique innovation based on nanotechnology can provide a durable graffiti protection on a wide range of surfaces at economical prices. The protection makes the application of lettering, images or signatures significantly more difficult, yet facilitates their removal without any harm to the ground surface.
\end{abstract}

\section{Damage due to graffiti in Germany and with Deutsche Bahn AG}

In the year 2014 alone, more than 35,000 acts of vandalism and graffiti were recorded throughout Germany. The damage caused by unauthorized graffiti on buildings and public transport vehicles is estimated to range between 200 million Euros and 500 million Euros per year. The annual expenses, including also prevention and taking out insurance, are even estimated to be a billion Euros.

In accordance with Czycholl, Harald (2011) [1], the economic damage resulting from acts of vandalism is 250 million Euros per year, as stated by the Deutscher Städtetag [German Cities and Communities Council], public transport accounting for half of this amount, private real estate for one third and public buildings for one fifth.

In accordance with the DB information service issue 03/2015, [2] Deutsche Bahn AG annually incurs damage of about 30 million Euros due to about 14,000 graffiti damage

\footnotetext{
* Corresponding author: dan.miricescu@ulbsibiu.ro
} 
cases; a new paint coat for a complete train costing up to 15,000 Euros and taking about seven days.

\section{Currently used systems - graffiti protection}

Although Deutsche Bahn AG uses protective paint coats and anti-graffiti film to protect their buildings and trains, the effort and environmental pollution for graffiti removal is enormous and cost-intensive. Despite the use of lacquer coats and so-called "sacrificial layers", from which graffiti can be removed more easily, DB incurs the high amount of damage as stated so that new technological innovations in terms of preventive graffiti protection are urgently required.

Basically with the presently used systems a distinction must be made whether these serve the removal of graffiti and cleaning or whether they provide protection in the form of a temporary or permanent coating which is to enable relatively simple cleaning.

Normally graffiti paint has a high percentage of solvents which can be absorbed particularly by absorbent grounds to a depth of several millimeters. Part of the non-absorbent grounds is attacked by the solvents to such a degree that the surface is damaged when removing them. Simultaneously, in addition to graffiti paint, marker pens and wax crayons as well as coaltar colors are used on smooth surfaces.

Spray can paint on the basis of acrylates and alkyd resins, which are available in almost all hues, are frequently used. Furthermore, products with binding agents such as polyalkene, polyvinyl acetate or copolymers or even two-component resins and oil paints are used.

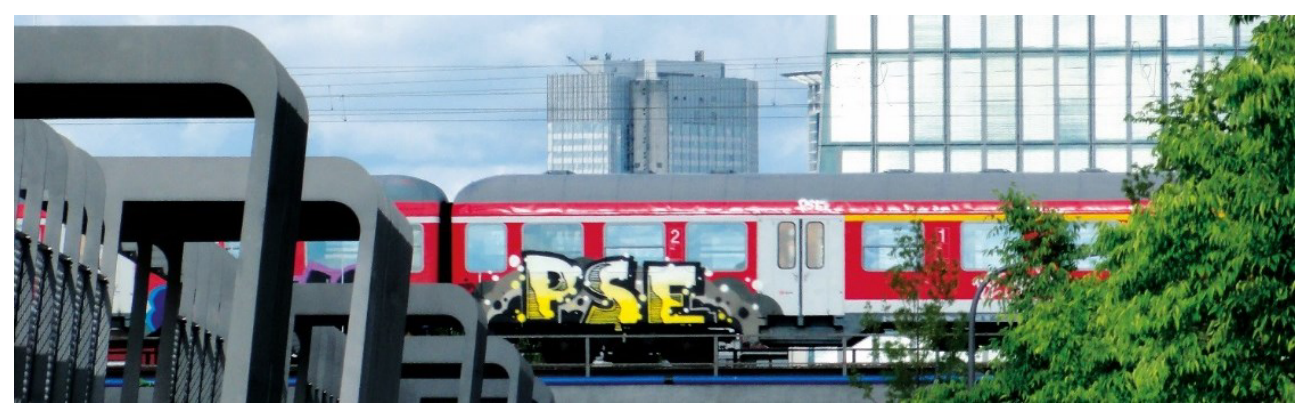

Fig. 1. Graffiti train close to Frankfurt/Main Central Station, Germany.

A particular challenge for anti-graffiti systems are hardly soluble silver, bronze and gold paints or felt-tipped pens which have a very high penetration into the ground. Increasingly car under seal in spray cans is used which can be removed - if at all - only with a great deal of effort and at great expenses.

There are different mechanical or chemical methods for removing undesired graffiti, e.g.:

- manual removal

- mechanical removal using the low-pressure wet sand blasting method

- chemically supported removal by hot water high-pressure jet

- removal by hot water high-pressure jet on grounds with a temporary or permanent coating

- laser technology

The use of temporary or permanent coatings depends heavily on the surface to be coated: mineral or organic, porous and optical.

Accordingly, different protective systems are feasible: 
- protective sealing with barrier layers

- temporary protective layers using sacrificial systems

- permanent protective layers using firmly adhering layers

- graffiti protection coats

- anti-graffiti film

Temporary sacrificial layers are cost-efficient protective layers which can be easily removed. However, such layers are high-maintenance as they have poor adherence qualities and their effect is reduced by mechanical damage.

In contrast, regular renewal of the layer is not necessary for permanent protective layers, which, however, have a low degree of water vapor permeability and in part tend to develop surface yellowing. In the case of a fire, poisonous carbon and nitrogen compounds can develop.

Graffiti protection coatings are normally applied to defaced surfaces; first a primary coat is applied, then it is coated with a fresh layer of paint. Such paint is commercially available in different hues and transparent.

Anti-graffiti film is used on glass and is as good as invisible. It is used on outdoor as well as indoor glass panes and are pulled off and replaced by new film when they were subjected to a spraying attack.

What all systems have in common is the fact that they do not (initially) prevent the spraying of graffiti, but (are meant to) facilitate graffiti removal.

\section{Nanotechnology}

What is desirable is an anti-graffiti system which either prevents the application of lettering, images ("pieces") or signatures ("tags") with spray cans or felt-tipped pens on the surfaces from the defaced surfaces from the outset and after cleaning of the surface, which should be as simple as possible, looks as it did before.

$\mathrm{B}+\mathrm{H}$ Solutions $\mathrm{GmbH}$ is a nanotechnology company focusing on the research, development, production and marketing of products containing nanoscaled materials against the backdrop that almost all chemical properties of any material result from its surface, not from its mass. For example, steel does not oxidize in the component core, but on the components outside on the surface. Almost all chemical reactions and compounds happen on the surface of the materials in question. This is an effect which nanotechnology uses, thus being able to generate new properties for a large number of materials. This generates new potential for new solutions in the event of low material resources.

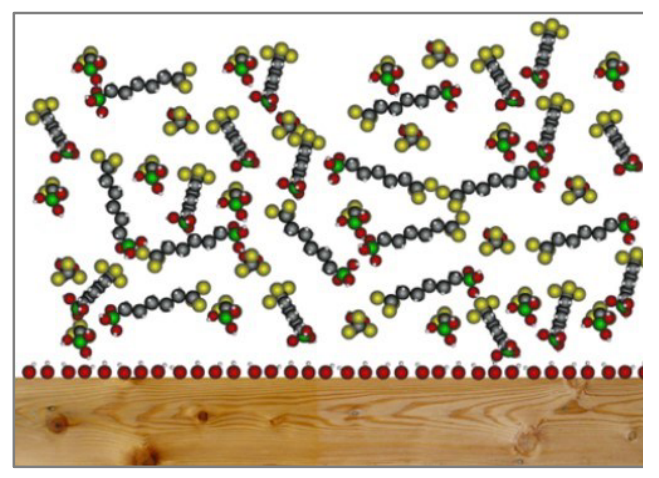

a

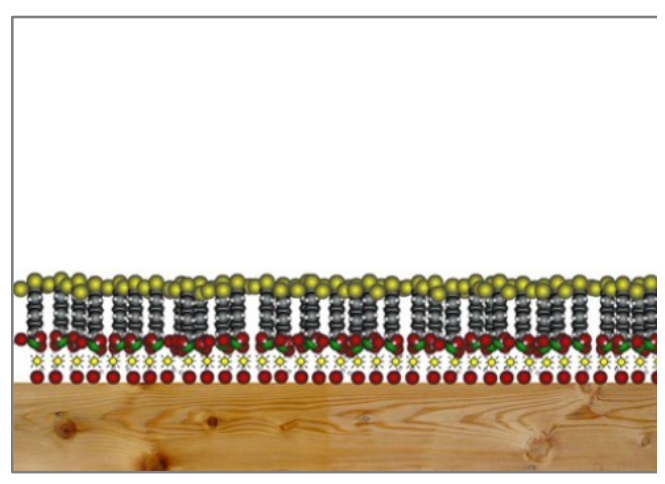

b

Fig. 2a. Orientation of the molecules when applying the coating (short moment), 2b. Molecules after application and drying of the coating; perfectly aligned = newly defined surface with new properties 
Significant for nanoparticles is the development of other properties, i.e. for example a larger surface relative to the mass, higher reactivity and another color (silver turns to yellow and gold turns to red).

Nanomolecules are self-orienting and contrary to microparticles which are spread on the surface in a nondirectional manner, are aligned. Such alignment ensures a consistent surface.

Nanotechnology enables the creation of new structures, e.g. a lotus effect structure which is water, oil and dirt repellent. Nanotechnology is extremely resource-friendly, as little mass can have great effect.

One of the products developed by B+H Solutions $\mathrm{GmbH}$ is $\mathrm{AGraffit}{ }^{\circledR}$. No paint (and no dirt) will stick to surfaces treated with $A$ Graffit ${ }^{\circledR}$ so that the sprayer cannot spray a clear image or pattern there, which will result in the sprayer quickly losing their motivation.

In addition to the product $\mathrm{AGraffit}{ }^{\circledR}$, there are many more technological innovations, and the company continues developing and formulating new products. Another mentionable product is ClearView intended for use on glass and ceramics. After its application water will simply roll off. Dirt cannot adhere any more. This considerably reduces the maintenance costs.

Compared to the products of other manufacturers, the product ClearView ${ }^{\circledR}$ stands out by it long durability, reducing the contamination of glass and ceramics and by the active combination of hydrophobisising (repellence of water) and oleophobisising (repellence of oil). This results in a self-cleaning effect in the event of torrential rain and/or enables cleaning of the surfaces with just water. When applied to photovoltaic systems, a clearly increased performance is stated due to the lower level of contamination of the element surfaces.

Furthermore, surfaces and coating layers can be coated in such a way that chewing gum will not stick to them anymore.

\section{Engineering innovation for preventive graffiti protection by $\mathrm{B}+\mathrm{H}$ Solutions $\mathrm{GmbH}$}

Thanks to the use of nanotechnology, the product AGraffit is doused with hydrophobic and oleophobic properties, which enable all grounds to be manufactured as repelling contamination, paints and solvents.

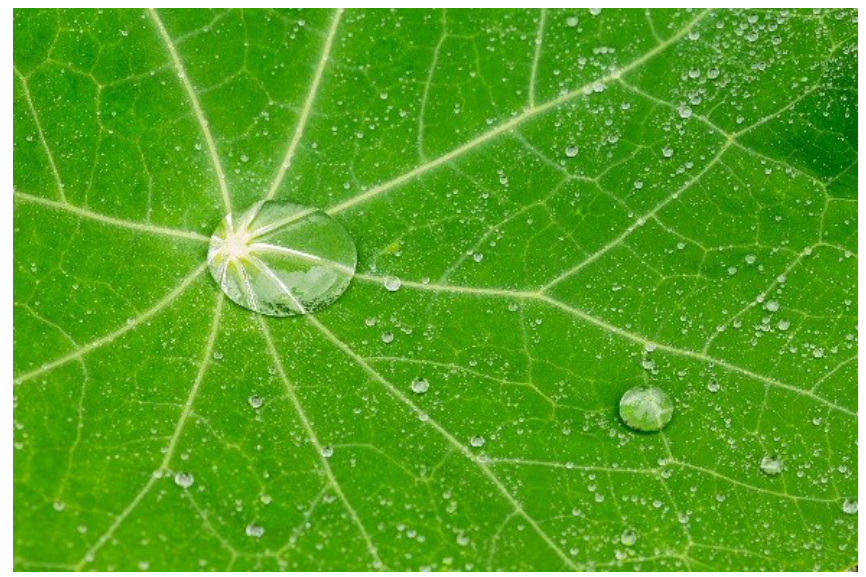

Fig. 3. Lotus effect you find in nature: Rolling-off of water 


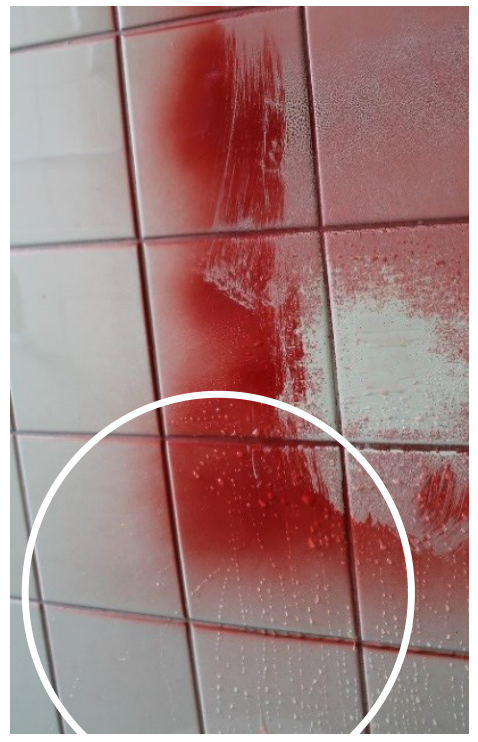

a

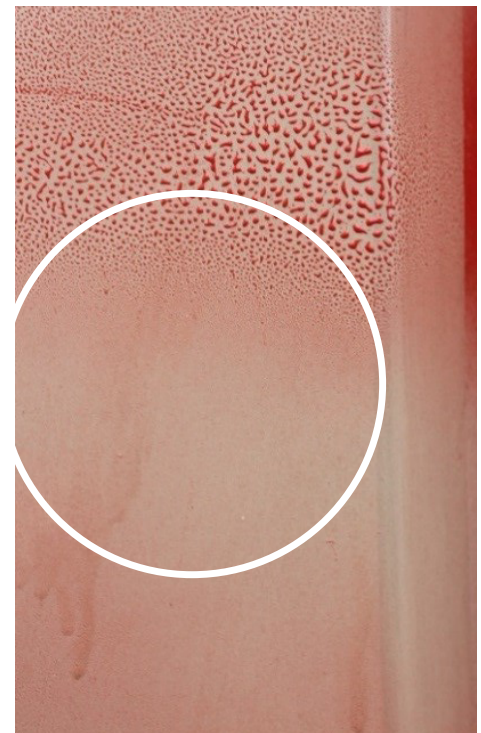

b

Fig. 4a. Tiles were pre-treated with AGraffit ${ }^{\mathbb{R}}$ in the test area (light-coloured area). It is clearly visible that the paint spray hardly adheres and can be removed without problem (white area). The rolling-off effect is clearly visible; $\mathbf{4 b}$. Application of $\mathrm{AGraffit}^{\mathbb{R}}$ on sheet metal

$\mathrm{AGraffit}^{\mathrm{B}}$ is a quickly drying one-component coat with excellent adherence on steel, aluminum, nonferrous metal, glass-fiber reinforced plastic, plastics and a large number of paints. It generates a surface which is neither shiny nor dull, yet highly weatherproof and resistant to ultraviolet light.

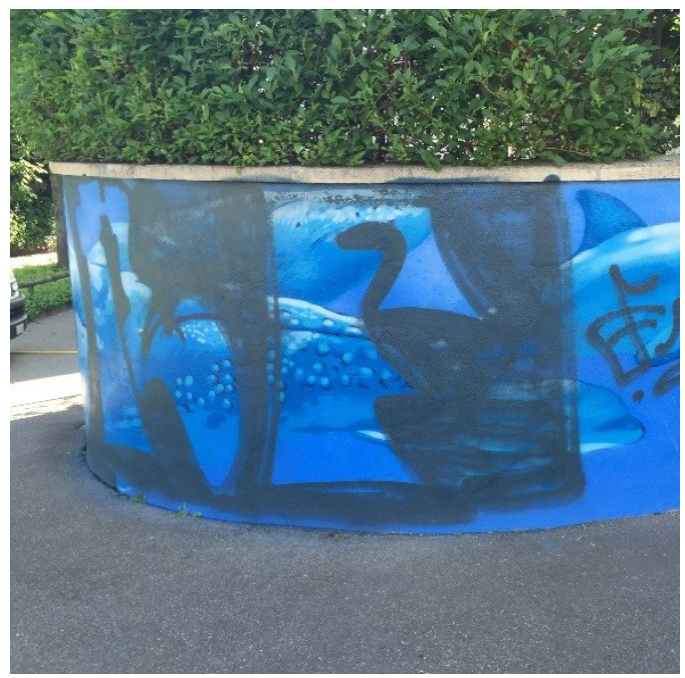

a)

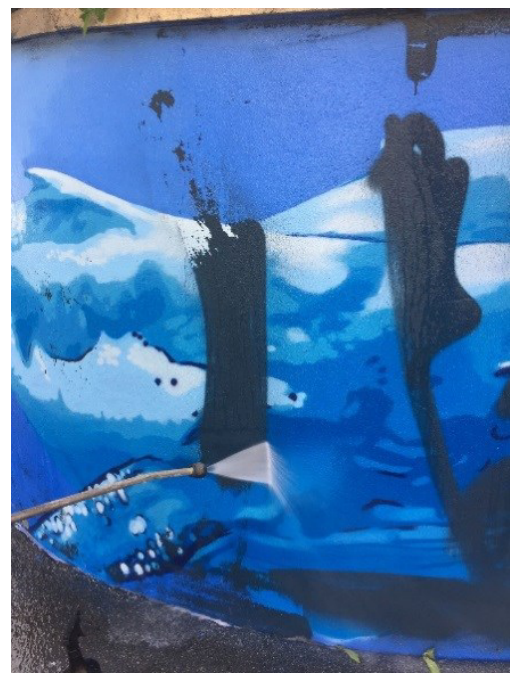

b) 


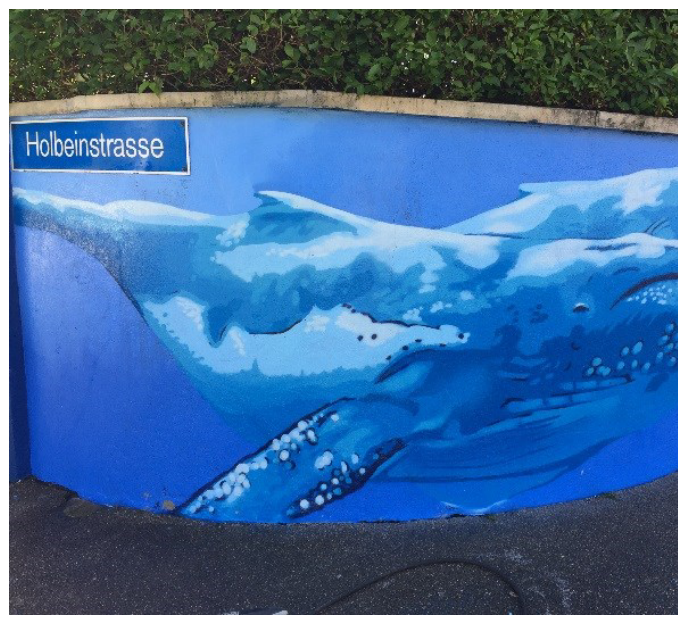

c)

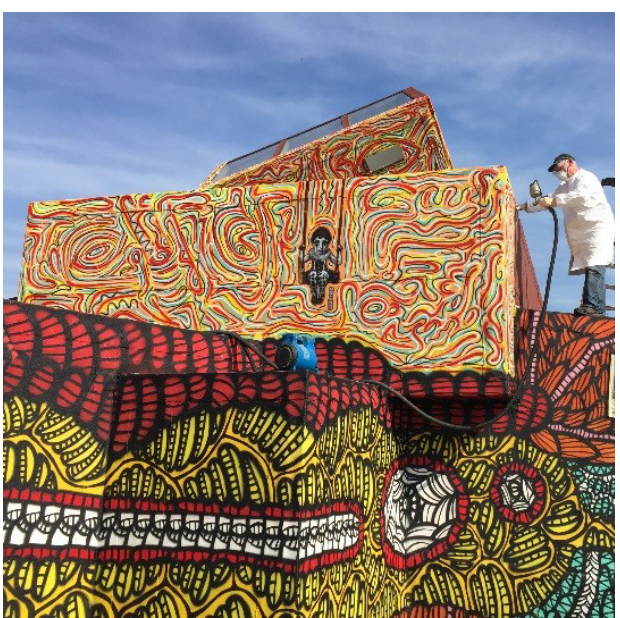

d)

Fig. 5a. Original position: Soiled surface of mural (concrete); 5 b. During cleaning process; $\mathbf{5 c}$. Result after cleaning; 5d. Prevention measures to protect genius art work

Sprayers cannot generate a precise image on the surface, the color rolls off. It is virtually impossible to spray lettering. Furthermore it is clearly visible that the paint can be removed without any problem.

Cleaning of surfaces treated with $\mathrm{AGraffit}^{\circledR}$ is simple and fast and in case of contamination requires nothing but water. If graffiti spray is dried, the manufacturer recommends the use of solvent (e.g. general-purpose thinner). The nano proofing will not suffer from cleaning; it is not a sacrificial layer. The effect of AGraffit ${ }^{\circledR}$ will remain unchanged.

\section{Application}

The product is applied on a dust-free ground by wiping it on with a cloth, rolling with paint roller or spraying with a layer thickness of 5 to $10 \mu \mathrm{m}$. On smooth and non-absorbent grounds, the manufacturer recommends applying the product with a cloth, on porous and absorbent grounds in an airless method, a thinner can be added, and the product should be applied in a cross layered pattern over the entire surface.

Depending on the degree of thinning and the type of thinner used, AGraffit ${ }^{\circledR}$ is dry after half an hour at room temperature and hard-dried after four hours and fully cured and chemically stable after seven days.

Forced drying and baking at 40 to $80^{\circ} \mathrm{C}$ is possible in order to achieve faster resistance to chemicals. It can be removed easily by using $120^{\circ} \mathrm{C}$ hot water vapors.

These products are tested in practice by the DB AG and already in use at train and suburban railway stations in and around Frankfurt/Main, Germany.

\section{Cost effectiveness}

The costs for the application of graffiti protection and/or graffiti removal to a large part depend on the circumstances of the individual case in question, i.e. on the size of the surface, the type and size of the ground, the accessibility of the location and of the fact whether the graffiti need to be removed from unprotected or protected surfaces. This means 
that the target prices cannot be quoted more accurately than within a wide scope. Depending on the type of ground, whether absorbent or not, one liter of AGraffit ${ }^{\circledR}$ protects a surface from 20 to 50 square meters.

\section{Summary}

This innovation can provide a durable graffiti protection on a wide range of surfaces at economical prices. The protection makes the application of lettering, images or signatures significantly more difficult, yet facilitates their removal without any harm to the ground surface.

\section{References}

1. H. Czycholl. Nur teure Zusatz-Police helfen gegen Graffiti - Only expensive additional policies help against graffiti, (Berliner Morgenpost, 2011)

2. J.-O. Voss, Kunst oder Straftat? Graffitischäden bei der DB - Art or criminal act? Graffiti damage with $D B$, DB Themendienst, 03 (2015) 